\title{
Avaliação funcional de monócitos em bovinos leiteiros infectados pelo vírus da leucemia bovina
}

José Augusto Ferronatto[a, $]^{[}$, Maiara Garcia Blagitz ${ }^{[b]}$, Fernando Nogueira de Souza ${ }^{[b]}$, Camila Freitas Batista ${ }^{[b]}$, Luis Fernando Fernandes Azevedo ${ }^{[b]}$,Alice Maria Melville Paiva Della Libera ${ }^{[b]}$

\footnotetext{
[a] Universidade do Oeste de Santa Catarina (UNOESC), Xanxerê, SC, Brasil

[b] Veterinary Clinical Immunology Research Group, Departamento de Clínica Médica, Faculdade de Medicina Veterinária e Zootecnia, Universidade de São Paulo (USP), São Paulo, SP, Brasil
}

${ }^{*}$ Autor correspondente

e-mail: jose_augustoferronatto@hotmail.com

\section{Resumo}

Os monócitos são importantes sentinelas para combater patógenos, contribuem para a defesa antimicrobiana e são críticos para a apresentação de antígenos para originar respostas imunes adaptativas específicas de antígenos. A infecção de monócitos por VLB desempenha um papel chave na patogênese, uma vez que estas células podem servir como reservatórios de infecção latente ou produtiva. Desta forma, o presente estudo objetivou avaliar a função dos monócitos sanguíneos em vacas leiteiras naturalmente infectadas pelo vírus da leucemia bovina (VLB) com e sem linfocitose persistente (LP). Para isto, o presente estudo utilizou 25 vacas Holandesas que foram separadas em três grupos: 1 - vacas não infectadas pelo VLB (resultados negativos nos testes de imunodifusão em ágar gel e ELISA para o antígeno gp51 do VLB) e sem alterações hematológicas (n = 9); 2 - vacas infectadas pelo VLB (resultados positivos nos testes de imunodifusão em ágar gel e ELISA para o antígeno gp51 do VLB) e sem alterações hematológicas [alinfocitóticos (AL), n = 10]; e 3 - vacas infectadas pelo VLB com LP (n = 6). Após 110 dias da primeira amostragem, foram feitas novas coletas para confirmar a LP, além de coletar amostras de sangue para determinar a fagocitose de Staphylococcus aureus, produção intracelular de espécies reativas de oxigênio (ERO), viabilidade e expressão de moléculas de adesão em monócitos por citometria de fluxo. Como resultados alcançados, as vacas infectadas pelo VLB com PL demonstraram alterações nas funções dos monócitos, como menor percentagem de monócitos que fagocitaram S. aureus, em contraste com a maior intensidade espontânea de produção intracelular de ERO. Além disto, observou-se inibição da apoptose de monócitos em animais infectados pelo VLB manifestando LP. A percentagem relativa de monócitos que expressaram CD44 foi mais baixa em vacas infectadas com BLV com PL $(46,30 \pm 2,52 \%)$ do que em animais sadios não infectados $(80,39 \pm 6,09 \%)$ e aqueles infectados 
pelo VLB sem alterações hematológicas $(78,16 \pm 5,53 \%)$. Além disso, a percentagem de monócitos CD44 $4^{+}$ foi positivamente correlacionada com a percentagem de monócitos que fagocitaram $S$. aureus $(r=0,43$; $\mathrm{P}=0,03$ ). Ademais, observou-se uma tendência a menor porcentagem dos monócitos que produziram ERO $(P=0,06)$ nos animais infectados pelo VLB com LP. Sabe-se que o CD44 foi considerado um receptor fagocítico competente, responsável por mediar de forma eficiente o reconhecimento de patógenos e a fagocitose, o que pode justificar a redução dos monócitos que fagocitaram S. aureus em vacas VLB infectadas com PL. Não encountrou-se alterações na expressão de CD62L e CD11b pelos monócitos sanguíneos nos animais infectados pelo VLB. Nossos achados apresentam algumas alterações imunológicas importantes, especialmente no que diz respeito aos monócitos, que podem predispor os animais a infecções secundárias. 